\title{
As concepções de integração curricular da EEEP Lysia Pimentel Gomes Sampaio Sales EEEP Lysia Pimentel Gomes Sampaio Sales curricular integration conceptions
} EEEP Lysia Pimentel Gomes Sampaio ventas concepciones de integración curricular

Recebido: 29/10/2019 | Revisado: 29/10/2019 | Aceito: 04/11/2019 | Publicado: 07/11/2019

\author{
Consolação Linhares de Carvalho Coelho \\ ORCID: https://orcid.org/0000-0002-06113829 \\ EEEP Lysia Pimentel Gomes Sampaio Sales, Brasil \\ E-mail: conlinhares20@gmail.com.br \\ Antônia de Abreu Sousa \\ ORCID: https://orcid.org/0000-0003-49704079 \\ Instituto Federal do Ceará, Brasil \\ E-mail: tonia_abreu@hotmail.com
}

\section{Resumo}

O presente estudo visa compreender o projeto de formação oferecido aos alunos da Escola Estadual de Educação Profissional (EEEP) Professora Lysia Pimentel Gomes Sampaio Sales, situada em Sobral no Ceará. Para tanto, analisamos, com base no método do materialismo dialético de natureza qualitativa, o Projeto Político Pedagógico da unidade de ensino, tendo por referência os conceitos de trabalho como princípio educativo, ciências, tecnologia e cultura (os eixos estruturantes do ensino médio) apresentados pelas Diretrizes Curriculares Gerais para Educação Básica. Constatamos que a referida escola é um espaço privilegiado para se estudar as disputar travadas entorno da formação do trabalhador, pois encontramos, no documento, concepções que tanto privilegiam a formação integral do aluno, como elementos que vão de encontro a tal formação e comprometem os interesses da classe trabalhadora.

Palavras-chave: Educação Profissional; Formação integrada; Emancipação.

\footnotetext{
Abstract

This study aims to understand the training project for students of the State School of Professional Education - EEEP Professor Lysia Pimentel Gomes Sampaio Sales, located in Sobral, Ceará. For this, we analyzed, based on the method of qualitative dialectical material of nature, the Pedagogical Political Project of the Teaching Unit, having as reference the concepts of work as Educational Principles, Sciences, Technology and Culture (the structured
} 
mechanisms of the High School). General Curriculum Guidelines for Basic Education. We find that the school is a privileged space to study as disputes fought in worker training, because no document is found, conceptions that both privilege the integral formation of the student, as elements that meet the training and compromise of working class interests. Keywords: Vocational Education; Integrated training; Emancipation.

\section{Resumen}

El objetivo de este estudio es comprender el proyecto de capacitación para estudiantes de la Escuela Estatal de Educación Profesional - Profesora de EEEP, Lysia Pimentel Gomes Sampaio Sales, ubicada en Sobral, Ceará. Para ello, analizamos, en base al método de material dialéctico cualitativo de la naturaleza, el Proyecto Político Pedagógico de la Unidad Docente, teniendo como referencia los conceptos de trabajo como Principios Educativos, Ciencias, Tecnología y Cultura (los mecanismos estructurados de la Escuela Secundaria). Pautas generales del plan de estudios para la educación básica. Encontramos que la escuela es un espacio privilegiado para estudiar, ya que las disputas en la capacitación de los trabajadores, porque no se encuentra ningún documento, concepciones que privilegien la formación integral del estudiante, como elementos que cumplen con la capacitación y el compromiso de los intereses de la clase trabajadora.

Palabras clave: Educación Vocacional; Capacitación Integrada; Emancipación.

\section{Introdução}

Compreender como uma determinada unidade de ensino concebe a integração entre a Educação Básica e a Educação Profissional é traduzir o projeto formativo que está sendo oferecido aos estudantes, uma vez que, ao ignorar tal integração curricular, a escola reforça a divisão entre trabalho manual e trabalho intelectual perpetuando e legitimando a desigualdade social e, por outro lado, na medida em que desenvolve ações pedagógicas que superam a dualidade entre teoria e prática, a escola garante uma formação emancipatória, dando aos estudantes condições para romper com a sua própria estrutura social e buscar a autorrealização por meio do domínio e da capacidade de articular os elementos conceituais das diversas áreas do conhecimento. Dessa forma, na perspectiva do ensino integrado, os jovens terão a possibilidade de assumir várias atividades profissionais, desde ocupações mais simples até aquelas que exijam o domínio de determinada ciência, bem como terão mais 
chances de alcançar a realização social plena e desenvolver uma consciência emancipatória que fortalecerá a luta da classe trabalhadora.

Pensar a educação a partir da luta emancipatória dos trabalhadores, seria, inevitavelmente, restabelecer o vínculo entre trabalho e ensino, conforme afirmou István Mészáros: "digam-me onde está o trabalho em um tipo de sociedade e eu te direi onde está a educação" ( 2008,p.17). O mesmo autor questiona sobre papel da instrução nos seguintes termos:

Será que a aprendizagem conduz à auto realização dos indivíduos como "indivíduos socialmente rico" humanamente ( nas palavras de Marx), ou está ela a serviço da perpetuação, consciente ou não, da ordem social alienante e definitivamente incontrolável do capital? Será o conhecimento o elemento necessário para transformar em realidade o ideal da emancipação humana, em conjunto com uma firme determinação e dedicação dos indivíduos para alcançar, de maneira bem sucedida, a autoemanciapção da humanidade, apesar de todas as adversidades, ou será, pelo contrário, a adoção pelos indivíduos, em particular, de modos de comportamento que apenas favorecem a concretização dos objetivos reificados do capital? Mészáros , p.47)

O fato é que a educação, em especial a educação profissional, sob o modo e produção capitalista, é um espaço de batalhas entre as classes dominadas e dominantes, prevalecendo, quase sempre, os interesses dominantes, embora alguns interesses da classe trabalhadora também sejam atendidos dependendo do contexto histórico em que se encerra a luta (Sousa, 2012). Portanto, a educação, no sistema capitalista, serve aos interesses da burguesia que procura formar o trabalhador para perpetuar a força de trabalho como mercadoria, mas não deixa de expressar as contradições inerentes do processo de disputa pela hegemonia do projeto de formação do trabalhador.

A partir dessas concepções iniciais, selecionamos a EEEP Professora Lysia Pimentel Gomes Sampaio Sales, entre as 122 escolas profissionais do estado do Ceará, para investigarmos o projeto de formação que está sendo oferecido aos atuais 495 alunos matriculados na referida instituição. Para tanto, analisamos as concepções de integração curricular presentes no Projeto Político Pedagógico-PPP da escola à luz dos conceitos de trabalho, ciências, tecnologia e cultura apresentados pelas Diretrizes Curriculares Nacionais Gerais para a Educação Básica- DCNEB, aprovadas em abril de 2010.

\section{Metodologia}


Compreender o projeto formativo proposto pela EEEP Lysia Pimentel Gomes Sampaio Sales, levando em consideração o vínculo entre trabalho/ensino e a luta emancipatória dos trabalhadores, conforme os referenciais já mencionados, nos levou a realização de uma pesquisa baseada no materialismo dialético de natureza qualitativa.

A pesquisa baseada no método do materialismo dialético, desenvolvido por Karl Marx ao estudar a sociedade do século XIX, possibilitou a análise crítica do objeto a ser pesquisado, uma vez que a compreensão do objeto contou com a contextualização e totalidade dos processos, estando os eventos relacionados uns com os outros de forma dialética no sentido de explicar a realidade. (Wachowicz, 2001, pp. 2-4).

A análise qualitativa, que “ . . . trabalha com o universo de significados, motivos, aspirações, crenças, valores e atitudes, o que corresponde a um espaço mais profundo das relações, dos processos e fenômenos que não podem ser reduzidos à operacionalização de variáveis.” (Minayo,2002, p. 22), ocorreu por meio do Estudo de caso, conforme as características gerais desse método de pesquisa pontuados por Marli Andre (1984), ao selecionarmos para nossa análise o documento norteador das práticas escolares, o Projeto Político Pedagógico-PPP da escola, sem ignorar o contexto no qual foi produzido.

\section{A EEEP Lysia Pimentel Gomes Sampaio Sales em seus aspectos gerais}

A EEEP Lysia Pimentel funciona há 7 anos em Sobral no interior do Ceará, ofertando os cursos técnicos de Fabricação Mecânica, Manutenção Automotiva, Logística e Administração integrados à base comum e estando entre as escolas profissionais do Estado que apresenta os melhores resultados tanto na inserção de alunos na Universidade como em empregabilidade, segundo o Projeto Político Pedagógico-PPP (2018) da escola.

O PPP da escola foi dividido em três marcos, sendo o primeiro o marco situacional que apresenta os aspectos gerais da escola e detalha os resultados; em seguida, temos o marco conceitual que apresenta a concepção de educação adotada pela escola; e o marco operacional em que detalha a rotina da unidade de ensino.

A escola foi construída, segundo os padrões arquitetônicos definidos pelo Ministério da Educação- MEC, apresentando uma estrutura de 5,5 mil metros quadrados de construção, 12 salas de aula, auditório, bloco administrativo, refeitório e laboratórios de Línguas, Informática, Química, Física, Biologia e Matemática. Há dois laboratórios técnicos, sendo um de Fabricação Mecânica no valor de 828.200,47 e outro de Manutenção Automotiva que custou 858.997.893. As instalações também possuem biblioteca, que permite a integração e 
ampliação dos conteúdos aprendidos em sala de aula, além de ginásio esportivo e teatro de arena, para estimular a prática esportiva e desenvolvimento de atividades culturais. A capacidade máxima dessa escola é de 540 alunos, estando matriculados atualmente, 496 estudantes (Escola Estadual de Educação Profissional Lysia Pimentel Gomes Sampaio Sales, 2018).

Ao todo, são 45 colaboradores atuando nesse espaço físico com o objetivo, segundo o PPP, de gerar resultados, sendo 05 professores efetivos, 14 temporários e 07 professores técnicos contratados pelo Instituto Centro de Ensino Técnológico- Centec. Já o núcleo Gestor é formado por seis integrantes: duas coordenadoras pedagógicas, uma coordenadora de estágio, um coordenador financeiro, uma secretária escolar, e a diretora. Quanto aos 13 funcionários, estão divididos em 2 exercendo funções administrativas, 4 nos serviços gerais, 2 na segurança armada da escola, 01 porteiro e 4 trabalhando na cozinha (Escola Estadual de Educação Profissional Lysia Pimentel Gomes Sampaio Sales , 2018).

$\mathrm{O}$ aluno entra na EEEP Lysia Pimentel às $7 \mathrm{~h}$ e permanece até 16h35min para receber a formação proposta pela matriz curricular de seu curso. Para que essas matrizes sejam implementadas, a escola funciona com nove aulas diárias, ocorrendo cinco aulas pelo turno da manhã e quatro pelo turno vespertino. Dentro dessa rotina pedagógica, as refeições são fornecidas por uma empresa terceirizada contratada pela Secretaria de Educação. Toda a alimentação produzida na escola é acompanhada por uma nutricionista. Essas refeições são realizadas em três momentos: às $8 \mathrm{~h} 40 \mathrm{~min}$, ocorre o lanche matinal dos alunos, o intervalo do almoço acontece no horário de $11 \mathrm{~h} 25 \mathrm{~min}$ as $13 \mathrm{~h}$ e o último lanche é servido às $15 \mathrm{~h} 30 \mathrm{~min}$ (Escola Estadual de Educação Profissional Lysia Pimentel Gomes Sampaio Sales, 2018).

No segundo semestre do terceiro ano, os alunos são encaminhados às mais de cinquenta empresas parceiras da escola para a realização dos estágios supervisionados, normalmente, no turno da tarde. Os estudantes são acompanhados nas empresas pelos orientadores de estágio e pelos coordenadores dos cursos, bem como recebem uma bolsa estágio e auxílio transporte. O Estágio curricular corresponde a uma disciplina do eixo de formação profissional com 300 horas de estágio, $40 \mathrm{~h}$ de mediação e 60 horas de projeto social desenvolvidos na escola para atender a formação da comunidade. Os projetos que a escola desenvolve são sugeridos pela própria Secretaria de Educação e são executados por toda equipe pedagógica, sendo Projeto Professor Diretor de Turma- PDT; Projeto Círculo de Leitura e Projeto Geração da Paz (Escola Estadual de Educação Profissional Lysia Pimentel Gomes Sampaio Sales, 2018). 
Quantos aos resultados internos (evasão, aprovação, reprovação e transferência) e os resultados externos ( Exame Nacional do Ensino Médio-ENEM, Sistema Permanente da Avaliação Básica do Estado do Ceará- SPAECE e Sistema de Avaliação da Educação BásicaSAEB), foi reservado no PPP uma extensa seção para expô-los, evidenciando que a escola lidera os resultados no Estado do Ceará (Escola Estadual de Educação Profissional Lysia Pimentel Gomes Sampaio Sales, 2018).

Esses resultados de natureza quantitativa não foram nosso objeto de estudo, mas são importantes para compreendermos como os valores e os conceitos que orientam a formação do sujeito impactam o desempenho acadêmico desses estudantes, sendo portanto um estudo a ser desenvolvido posteriormente. Nesse artigo, como já mencionamos, nos limitaremos ao estudo, tendo por base os eixos estruturantes do ensino médio, das concepções formativas que orientam os processos pedagógicos da EEEP Lysia Pimentel Gomes Sampaio Sales.

\section{Os Eixos estruturantes do Ensino Médio como base para a integração curricular}

Segundo as Diretrizes Curriculares Nacionais para Educação Básica (2013), o desenvolvimento pleno dos sujeitos somente será garantido mediante a incorporação pelas redes e unidades de ensino de um currículo integrado, estruturado pela noção de trabalho, ciências, tecnologia e cultura, uma vez que tais noções representam as dimensões da formação humana.

$\mathrm{Na}$ elaboração de um projeto formativo para o ensino médio, as Diretrizes compreendem o trabalho como princípio educativo a partir da dimensão ontológica, na medida em que:

. . proporciona a compreensão do processo histórico de produção científica e tecnológica, como conhecimentos desenvolvidos e apropriados socialmente para a transformação das condições naturais da vida e a ampliação das capacidades, das potencialidades e dos sentidos humanos. O trabalho, no sentido ontológico, é princípio e organiza a base unitária do Ensino Médio. ( Brasil, 2013, p. 162)

O trabalho é compreendido como realização inerente ao ser humano, pois é por intermédio do trabalho, diferentemente dos outros animais, que o homem transforma a natureza adaptando-a as suas necessidades. Para tanto, ele se apropria do conhecimento produzido pela humanidade para reformulá-lo e aplicá-lo na mediação de sua existência. Esses conhecimentos sistematizados, produzidos socialmente no curso da história, na busca da compreensão e transformação da natureza e da sociedade, são definidos, pelas Diretrizes, 
como Ciências, que, por sua vez, ao serem apropriados como força produtiva, sintetizam o conceito de Tecnologia, que representa a “. . . mediação entre conhecimento científico (apreensão e desvelamento do real) e produção (intervenção no real).” (Brasil, 2013, p. 162).

Esse processo relacional entre ciências e tecnologia originado do trabalho ocorre orientado por uma determinada cultura, que significa um conjunto de normas de conduta de uma sociedade, expressas pelos valores éticos e estéticos, correspondendo às manifestações materiais e simbólicas que constituem o modo de vida de uma população específica.

Essas categorias são os referenciais básicos para a efetivação das atividades interdisciplinares, compreendidas, pelas Diretrizes (2013), como abordagem teóricometodológica direcionada para a integração das distintas áreas do conhecimento. Sendo assim, a organização curricular do ensino médio, pautada na interdisciplinaridade, ocorre por meio das

. . disciplinas (recorte do real para aprofundar conceitos) e com atividades integradoras (imersão no real ou sua simulação para compreender a relação parte-totalidade por meio de atividades interdisciplinares). Há dois pontos cruciais nessa proposta: a definição das disciplinas com a respectiva seleção de conteúdos; e a definição das atividades integradoras, pois é necessário que ambas sejam efetivadas a partir das inter-relações existentes entre os eixos constituintes do Ensino Médio integrando as dimensões do trabalho, da ciência, da tecnologia e da cultura. ( Brasil, 2013 p.184).

Quanto à seleção das disciplinas e definição das atividades integradoras, o documento orienta para que o foco seja no estudante e atenda sempre ao ensino-aprendizagem baseado nos eixos estruturantes do ensino médio. No texto das Diretrizes, não há uma indicação clara de quais seriam as atividades integradoras, mas ele indica que cada escola e sistema de ensino devem ter como referência para a elaboração e execução dessas atividades a realidade dos seus estudantes.

Para Moura (2012), a pretendida integração curricular, tendo por base os eixos estruturantes do ensino médio, precisa ir além de proporcionar o acesso ao conhecimento científico e tecnológico elaborado e apropriado pela humanidade. Precisa estimular a capacidade do aluno para analisar criticamente as manifestações culturais ao longo da história, como forma de compreender as especificidades de cada sociedade, desenvolvendo o respeito pela diversidade e construir novos paradigmas de produção que atendam aos interesses da coletividade.

A partir dos eixos estruturantes do ensino médio, como base integradora do currículo, analisaremos, na próxima seção, as concepções formativas presentes no PPP da EEEP Lysia 
Pimentel Gomes Sampaio Sales.

\section{Perspectiva de formação expressa no projeto político pedagógico da EEEP Lysisa Pimentel Gomes Sampaio Sales}

No marco conceitual do PPP, é possível identificar as concepções de formação da EEEP Lysia Pimentel, baseadas na Lei de Diretrizes e Bases da Educação- LDB, na Tecnologia Empresarial Socioeducacional-TESE e no Relatório de Gestão: “ O pensar e o fazer da educação profissional no Ceará-2008 a 2014", além de ser feita referência a Acácia Kuenzer e a Jurjo Torres Santomé.

A TESE é uma proposta educacional empresarial baseada no modelo de gerenciamento da empresa brasileira Odebrecht que atua nos setores de engenharia, infraestrutura, energia entre outros. Essa proposta compreende a escola como uma empresa, tanto no aspecto linguístico como de procedimento, o que não tem o caráter desinteressado, mas alinhado aos valores do capitalismo em suas feições contemporânea, conforme a análise de César Lima Costa:

A TESE como proposta educacional empresarial tende, "mediaticamente", a dar continuidade ao processo neoliberal com "novas" nuanças, pois continua classicamente reafirmando a ineficiência do Estado, como instituição capaz de implementar políticas públicas necessárias à equalização dos problemas sociais, de um lado, e de outro, se oferece como parceiro no processo de gestão do sistema de ensino, mediante mecanismos que garantam formas ' eficiente e eficazes' de formação humana, elidindo a ideia de que tais mecanismos consistem em processos regressivos de empresariamento da sociedade que racionalizam as forças de trabalho sob o mote da produção flexível. . . ( Costa, 2012, p. 129)

Essas formas "eficientes e eficazes" de formação humana sugeridas pela TESE estão frontalmente em oposição aos princípios de uma formação integral, desconsiderando completamente os eixos estruturantes do ensino médio no processo de ensino, ao passo que supervaloriza os resultados de avaliações externas em que os alunos são treinados para responder determinado modelo de questões, bem como fortalece um processo de aprovação mecânica do aluno para as séries subsequentes sem atender aos devidos critérios de aprendizagem, mas garantido os números necessários para celebrar o aparente sucesso da educação, assim como se a qualidade da educação fosse mensurada somente pelos aspectos quantitativos como em uma empresa o sistema capitalista.

O Relatório de Gestão, também referenciado no PPP da escola, foi um documento 
publicado, em 2014, pela Coordenadoria de Educação Profissional do Ceará com o objetivo de narrar os conceitos, ideias e feitos das Escolas de Educação Profissional e da Política de Educação Profissional que vinha sendo constituído na gestão do então governador Cid Gomes. No sentido de ensejar à nova gestão que se iniciou com o Governador Camilo Santana, em 2015, o acesso ao conhecimento já produzido no campo da Política Pública de Educação Profissional e chamando atenção sobre os desafios que sua continuidade e implementação requerem (Seduc, 2014).

No documento estadual supracitado, disputam espaços tanto as idéias de formação integral do sujeito, referenciadas pelo trabalho como princípio educativo, ciências, tecnologia e cultura que possibilitariam a organização de práticas pedagógicas contextualizadas e interdisciplinares, como as concepções de formação para o capital, baseada nos resultados das avaliações externas e na formação de técnicos para atender as demandas do mercado, além das referências explícitas à TESE (Seduc, 2014). Esse antagonismo presente no texto revela as contradições inerentes às disputas entre dominados e dominadores pelo controle da formação da classe trabalhadora.

Segundo o PPP, a ideia de educação que norteia as práticas dos profissionais da escola está fundamentada no art $2^{\circ}$ da LDB:

Os princípios da educação são inspirados nos ideais de liberdade e solidariedade humana. Sendo a liberdade compreendida como a capacidade de emancipação, de ter a possibilidade de escolha, de decisão, de julgar por si mesmo, sem ser constrangido ou obrigado a algo pela determinação natural ou social. $O$ aluno deve compreender que a liberdade não é licenciosidade em que cada qual faz o que quer, mas fazer o que se deseja no âmbito das normas coletivas convencionadas. E a solidariedade humana é trabalhada como um princípio fundamental para o crescimento da coletividade, assegurando o bem-estar de todos. Sabendo que a finalidade maior da educação, segundo a LDB, é o pleno desenvolvimento do educando (grifo nosso) e seu preparo para o exercício da cidadania e sua qualificação para o mundo do trabalho, o jovem é visto de forma holística, onde todas as dimensões do ser humano são trabalhadas, superando a educação conteudista. As disciplinas da parte diversificada, Projeto de Vida, Mundo do Trabalho, Empreendedorismo e Formação para a Cidadania e Desenvolvimento das Competências Socioemocionais, possibilitam desenvolver o educando para além dos conhecimentos acadêmicos. (Escola Estadual de Educação Profissional Lysia Pimentel Gomes Sampaio Sales, 2018, p 11)

Sendo assim, o PPP propõe o pleno desenvolvimento do educando, fundamentado nos princípios de liberdade e solidariedade humana, e para tanto "a escola adota o currículo 
integrado, segundo as orientações da SEDUC expressas no Relatório de Gestão: o pensar e o fazer da Educação Profissional no Ceará-2008 a 2014.” ( Escola Estadual de Educação Profissional Lysia Pimentel Gomes Sampaio Sales, 2018, p.12). Portanto, o PPP incorpora as mesmas contradições presentes no Relatório de Gestão, evidenciando as disputas entre uma formação baseada nos eixos estruturantes do ensino médio e uma formação para atender aos interesses mercadológicos.

Retomando o Relatório de Gestão, o PPP reconhece ser um desafio o processo de integração efetiva entre as disciplinas da base nacional comum e da base técnica, não sendo somente um desafio de reestruturar a proposta curricular, mas de “. . . fortalecer a prática do professor, criar possibilidade de mudança em sua prática pedagógica e contribuir para que o aluno possa realizar a integração curricular de forma contextualizada e interdisciplinar." (Seduc, 2014 como citado em Escola Estadual de Educação Profissional Lysia Pimentel Gomes Sampaio Sales, 2018, p. 13).

Para o PPP (2018), a integração ocorre no dia a dia da escola por meio das alternativas encontradas pelos professores e alunos para superar as abordagens metodológicas tradicionais, apontando para uma prática de ensino que supere a dicotomia entre as disciplinas da base comum e da base técnica, sendo adotada a interdisciplinaridade como um processo e uma filosofia de trabalho que entraria em ação por meio da atitude de cada docente ao trabalhar em equipe para estabelecer um ensino que não reduza as explicações dos fenômenos estudados a uma única abordagem conceitual. E, como interdisciplinaridade, o documento compreende ser:

[...] uma vontade e compromisso de elaborar um contexto mais geral, no qual cada uma das disciplinas em contato é por sua vez modificada e passa a depender claramente umas das outras. Aqui se estabelece uma interação entre duas ou mais disciplinas, o que resultará em intercomunicação e enriquecimento recíproco e, consequentemente, em uma transformação de suas metodologias de pesquisa, em uma modificação de conceitos, de terminologias fundamentais. (Santomé, 1998 como citado em Escola Estadual de Educação Profissional Lysia Pimentel Gomes Sampaio Sales, 2018.p.13)

É por meio dessa perspectiva interdisciplinar que se efetiva o currículo integrado conceituado no PPP como:

. . . uma visão progressista da educação à medida que não separa o conhecimento acumulado pela humanidade na forma de conhecimento científico daquele adquirido pelos educandos no cotidiano das suas relações culturais e materiais. Por essa razão, possibilita uma abordagem darealidade como totalidade, permitindo um cenário favorável a que todos possam 
ampliar a sua leitura sobre o mundo e refletir sobre ele para transformá-lo no que julgarem necessário. $\mathrm{O}$ ensino integrado tem por objetivo disponibilizar aos jovens que vivem do trabalho a nova síntese entre o geral e o particular, entre o lógico e o histórico, entre a teoria e a prática, entre o conhecimento, o trabalho e a cultura. (Kuenzer,2000 como citado em Escola Estadual de Educação Profissional Lysia Pimentel Gomes Sampaio Sales, 2018.p.13).

Então, para o documento supracitado, o currículo integrado traduz uma educação comprometida com a emancipação do jovem, pois as articulações das áreas do conhecimento e o estreitamento das relações entre teoria e prática podem contribuir para ampliar a capacidade do aluno a fim de analisar e compreender os processos históricos-sociais da produção do conhecimento, bem como solucionar problemas próprios da realidade contemporânea, que exigem o manejo de informações e habilidades globais que uma formação fechada em conceitos disciplinares restritos não o capacitaria para equacionar a situação que lhe foi imposta.

No PPP (2018), entretanto, em flagrante oposição ao princípio de formação integral do ser humano, há referência à TESE como sendo um modelo de gestão que garante os altos resultados da escola por meio do desenvolvimento de competências como as contidas no Relatório de Jacques Delors, denominadas pilares do conhecimento: aprender a conheceradquirir os instrumentos da compreensão; aprender a fazer- poder agir sobre o meio envolvente; aprender a viver juntos (conviver)- participar e cooperar com os outros em todas as atividades humanas; aprender a ser- realizar-se como pessoa em sua plenitude.

O modelo da formação para as competências surgiu no discurso do empresariado francês e foi incorporado por grupos comprometidos com a reestruturação administrativa. (Cardozo, 2014) Segundo Dubar citado por Cardozo, o conceito de competência “ [...] corresponde a uma concepção das relações sociais de trabalho que valoriza a empresa e o contrato individual de trabalho" ( 2014, p.160), ou seja, enfraquece as relações coletivas e, consequentemente, a luta dos trabalhadores pela emancipação, pois cada indivíduo será responsável pelo seu emprego, buscando, individualmente, desenvolver habilidades para adaptar-se às exigências das empresas.

Podemos constatar que no PPP da EEEP Lysia Pimentel ocorre uma "confusão" conceitual sobre o processo formativo do sujeito na medida em que, de um lado, temos a busca por uma integração curricular para garantir uma formação omnilateral ao aluno por meio da interdisciplinaridade com base nos eixos estruturantes do ensino médio, mas, por outro lado, observamos o empresariamento dos processos educacionais com a incorporação dos princípios e valores da TESE, assim como a defesa pela formação para as competências 
no sentido de preparar o jovem de formar flexível para atender as demandas do mercado. Portanto, podemos concluir que a EEEP Lysia Pimentel é um espaço privilegiado para observamos as disputas, travadas entre dominados e dominadores, entorno da formação da classe trabalhadora. Entendemos que a análise do PPP é só o início para desvelar os meandros dessa batalha que, na maioria das vezes, ocorre de forma silenciosa no dia a dia da escola.

\section{Considerações finais}

Esse estudo identificou as disputas ideológicas, entorno da formação do trabalhador, que influenciam as práticas pedagógicas orientadoras da construção das identidades e dos perfis profissionais dos estudantes, possibilitando, dessa forma, aos profissionais da educação repesarem suas abordagens, adotando posturas conscientes em favor da emancipação do sujeito.

Os atuais 495 alunos matriculados e os mais de 600 egressos, filhos da classe trabalhadora, recebem e receberam, na EEEP Lysia Pimentel, uma formação que tanto admite princípios de preparação para o mercado, com a incorporação dos ideais da TESE, como concebe um currículo integrado, tendo por base as concepções de interdisciplinaridade baseadas nos eixos estruturantes do ensino médio, visando a formação omnilateral do sujeito, conforme constatamos ao analisar o texto e os referências do Projeto Político Pedagógico da unidade de ensino. Esse antagonismo revela as disputas entorno da formação da classe trabalhadora e a tomada de consciência desse contexto por parte dos profissionais da educação é importante para assegurar posturas pedagógicas conscientes e comprometidas seja com o projeto de formação emancipatório ou mesmo com a formação para o capital. Entendemos que o estudo do PPP nos revelou muito, mas é apenas o início do processo investigativo que precisa ser aprofundado por meio do estudo de campo que identifique as práticas e conteúdos de ensino que orientam a construção curricular no sentido da integração com base no trabalho como princípio educativo, ciências, tecnologia e cultura e, por outro lado, também é preciso entender as ações pedagógicas que vão de encontro à formação integral do sujeito, comprometendo os interesses da classe trabalhadora. Portanto, a EEEP Lysia Pimentel é um espaço de pesquisa que precisa ser explorado para compreendermos, a partir da observação da rotina escolar, como ocorrem, na prática, as disputas pela formação dos trabalhadores.

\section{Referências}

Andre, M.E.D.A. (1984). Estudo de Caso: seu potencial na educação. Cad. Pesq,49,51-54. 
Brasil. (1996). Lei n.9.394, de 20 de dezembro de 1996. Diretrizes e Bases da Educação Nacional. Brasília. Disponível em:http://www.planalto.gov.br/ccivil_03/LEIS/L9394.htm. Acesso: 23 de Julho de 2019.

Brasil. (2013). Diretrizes Curriculares Nacionais Gerais da Educação. Brasília: MEC, SEB, DICEI.

Cardozo, M.J.P.B. \& Arrais Neto, E.A. (2014). O ensino Médio e a Formação do Trabalhador: competências para quem e para quê? In: Sousa, A.A. \& Oliveira, E.G. (Orgs). Educação Profissional: Análise Contextualizada. Fortaleza: Edições UFC.

Costa, C. L. (2012). A integração do ensino médio à educação profissional técnica no Brasil e os rebatimentos no Estado do Ceará: da aparência à essência. (Dissertação de Mestrado). Universidade Federal do Ceará-UFC, Fortaleza, CE, Brasil.

Escola Estadual de Educação Profissional Lysia Pimentel Gomes Sampaio SalesEEEP.(2018). Projeto Político Pedagógico-PPP. Ceará.

Mészáros, I. (2008). A educação para além do Capital. (2a.ed). São Paulo: Boitempo.

Minayo, M. C. S. (Org). (2002). Pesquisa Social: Teoria, método e criatividade. Petrópolis: Editora Vozes.

Moura, D. (2012). A organização curricular do Ensino Médio Integrado a partir do eixo estruturante: Trabalho, Ciência, Tecnologia e cultura. Revista Labor, Ceará, 7(1): 1-19.

Secretaria de Educação do Estado do Ceará. (2014). Relatório de Gestão "O pensar e o fazer da educação profissional no Ceará - 2008 a 2014”. Fortaleza.

Sousa, A. A. (2012). Expansão da Educação Profissional no Brasil: Análise dos Institutos Federais de Educação, Ciências e Tecnologia- IFS. In: A. A. Sousa; E. G. de Oliveira; E Arrais \& M. Bessa (Orgs). Educação e Formação para o trabalho no Brasil. Fortaleza: Edições UFC. 
Wachowicz, L. A. (2001). A Dialética na Pesquisa em Educação. Revista Diálogo Educacional-v.2- n.3- p.171-181.

\section{Porcentagem de contribuição de cada autor no manuscrito}

Consolação Linhares de Carvalho Coelho - 70\%

Antônia de Abreu Sousa - 30\% 